\title{
Influence of modern technogenic conditions on historical urban territories
}

\author{
Olga Yanina, ${ }^{1, *}$, Alexander Yanin ${ }^{1}$, and Anton Chigarev ${ }^{1}$ \\ ${ }^{1}$ Voronezh State Technical University, Voronezh 394006, Russian Federation
}

\begin{abstract}
Preservation of buildings - objects of cultural heritage in modern technogenic urban conditions is currently an urgent task for cities with historical territories. The aim of this work was to examine and monitor the soil base of the foundations of a building - a cultural heritage site located in the central part of the historical territory of Voronezh. In the study, the influence of modern technological conditions prevailing in the historical territory on the change in the properties of base soils of the building's foundations and the development of slope processes was established. The results of the study can be used in the development of projects for monitoring base soils and geotechnical processes to ensure maximum preservation of the historical object and the optimal implementation of the building in a new function.
\end{abstract}

\section{Introduction}

The adaptation of historical urban development to the modern needs of society is an instrument for preserving the historical and cultural heritage of our country, which is an important part of the cultural memory of society, forms the national and historical identity of the Russians [1]. The urgent task of engineering and geological surveys while preserving and adapting buildings - objects of cultural heritage to the modern needs of society is to study the impact of modern technogenic urban conditions on them.

\section{Materials and methods}

The study of the influence of modern technological conditions on the change in the properties of the foundation soils was carried out on the example of the residential building "Skuratova House" - an object of cultural heritage in Voronezh (Fig. 1).

\footnotetext{
* corresponding author: yaninaoi@yandex.ru
} 


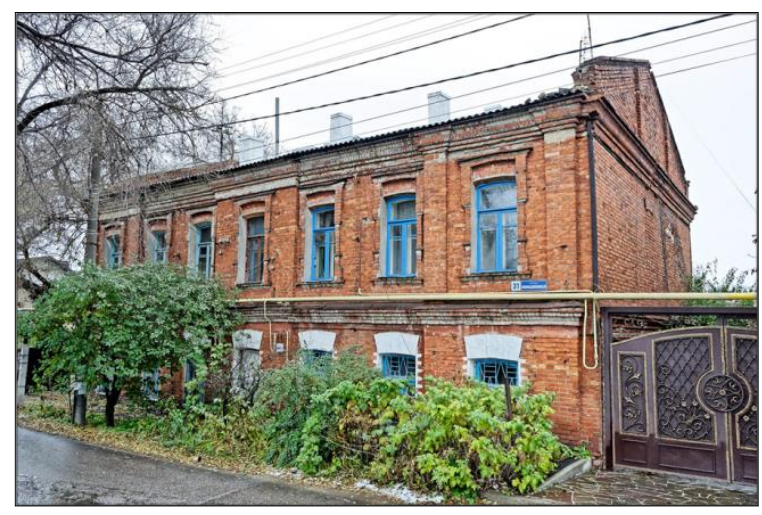

Fig. 1. General view of the building of "Skuratova House".

The residential building was built in 1901 by an unknown architect in the late 19th century. The town-planning historical value of the building lies in the fact that it forms, in combination with stairs, retaining walls and greenery of the gardens, the picturesque historical environment of old Voronezh. This building is an example of ordinary low-rise buildings on the coastal slopes of the Voronezh River in the central part of the city.

The modern technogenic conditions of the site of the building "Skuratova House" are determined by the conditions of a dense low-rise historical urban development that formed in the 19th...20th centuries. The building is located in the middle of the slope of the right bank of the Voronezh River between Aviatsionnaya and Bekhterev Streets.

Geomorphologically, the site is confined to the fourth right-bank floodplain terrace of the Voronezh River. The surface of the site has a significant slope: along Aviatsionnaya street $-10^{\circ}$; along Bekhterev street $-32^{\circ}$. In the upper part of the slope, a nine-story residential building was built in 2001 .

The soil survey of the base of the building was carried out in 2013 and 2018 in several stages:

- at the first stage, archival materials were studied and a research program was developed [2, 3, 4];

- at the second stage, 5 pits were made near the foundations inside the building in the basement with a depth of $0.95 \ldots 1.30 \mathrm{~m}$. Wells of $4.5 \ldots 5.0 \mathrm{~m}$ were drilled from the bottom of the pits. 20 samples of undisturbed structure were taken from the pits $[5,6,7]$. Foundation structures were examined in the pits;

- at the third stage, laboratory studies of the physical and mechanical properties of the foundation soils were performed [8,9] and monitoring of their changes over the period 2013-2018 [10];

- at the fourth stage, the slope stability calculations were performed in the GTS NX MIDAS software package.

\section{Results}

According to the results of the study of the physical and mechanical properties of the soils at the base of the building foundations, three engineering-geological elements (EGE) were identified [11, 12]: EGE-1, tQ $\mathrm{IV}_{\mathrm{IV}}$ - filled soil; EGE-2, $\mathrm{aQ}_{\mathrm{II}}$ - sand of medium size, medium density, low degree of water saturation; EGE-3, $\mathrm{aQ}_{\mathrm{II}}$ - sand of medium size, dense, low degree of water saturation.

In the pits, the foundations of the walls of the building were examined: strip, of rubble stone - sandstone of irregular "ragged" shape with inclusions of fragments of ceramic brick 
in lime mortar. The width of the foundation beds of the external and internal bearing walls is $0.50 \ldots 1.00 \mathrm{~m}$. The depth of the foundation beds $-0.35 \ldots 0.70 \mathrm{~m}$ in the basement part og the building; $1.67 \mathrm{~m}$ - in the part without the basement. A decrease in the strength of the foundation masonry mortar below the level of the basement floor to M4 was noted.

Cracks were noted in the masonry of the walls of the building and their further development was determined for the period 2013...2018. The greatest presence and opening of the cracks on the walls of the side facades of the building: $2 . . .3 \mathrm{~mm}$ in the lower part of the wall; in the upper part of the wall - up to $5 \ldots 8 \mathrm{~mm}$. The cracks pass from the bottom of the wall to the eaves of the building and have a complex vertically inclined direction with branches (Fig. 2).
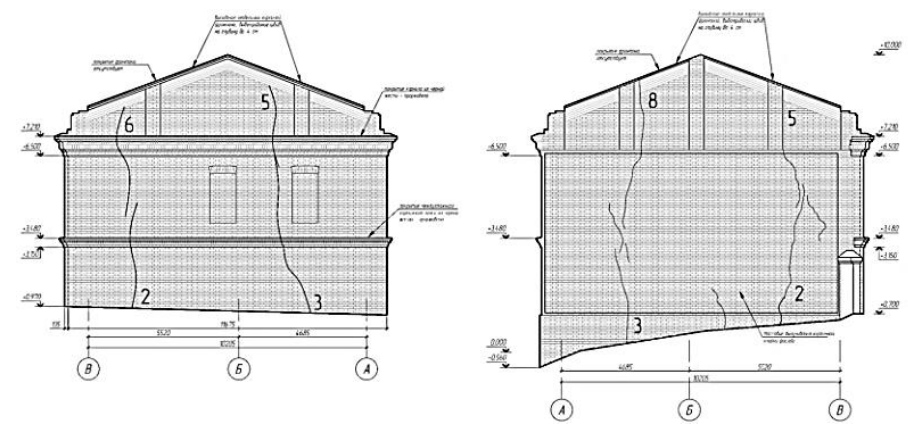

Fig. 2. Cartogram of cracks on the side facades of the building (2018).

The results of monitoring changes in the physical properties of sandy soils of the building foundations for the period from 2013 to 2018 are shown in the diagrams in Fig. 3.
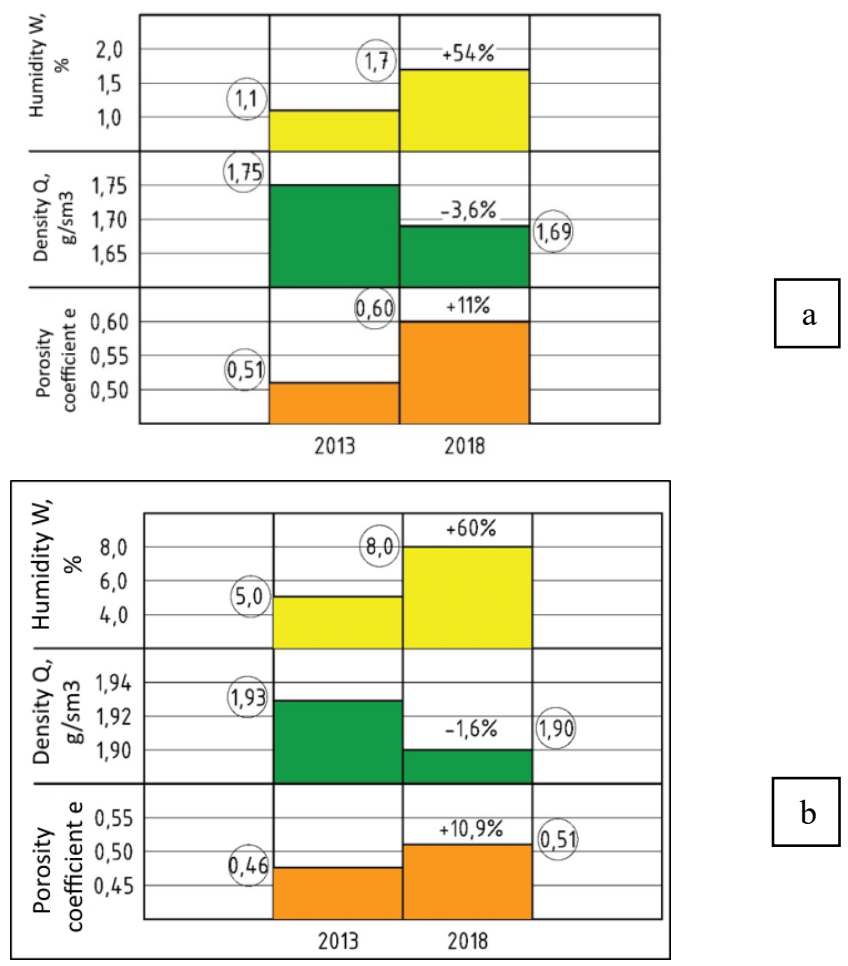

Fig. 3. Diagram of changes in the physical characteristics of the building base soils where a is the sand of EGE-2; $b$ - the sand of EGE-3. 
The analysis of the results of determining the physical properties of base soils for the period 2013...2018 showed changes in the properties of sandy soils of the building base. For the sand (EGE-2) and sand (EGE-3), the greatest change in humidity $\mathrm{W}$ for $54.5 \ldots 60 \%$ was noted; and the porosity index increased by $11 \%$.

Based on the results of the research and monitoring of base soils and construction of foundations and walls, the stability of the slope of the building location area was calculated $[13,14]$. To calculate the stability of the slope in the GTS NX MIDAS software package, the following initial scheme was chosen (Fig. 4): the building is located in the middle part of the slope; in the upper part of the slope, a distributed load of $\mathrm{q}=50 \mathrm{kN} / \mathrm{m}^{2}$ from the constructed multi-storey residential building is set; the angle of inclination of the slope surface is $32^{\circ}$; the standard value of the stability coefficient $\mathrm{K}_{\mathrm{stn}}=1.2$ (Fig. 5).

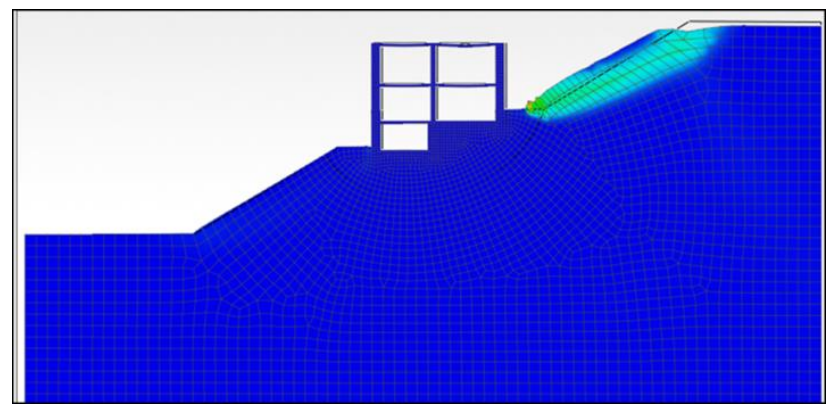

Fig. 4. The initial scheme for calculating slope stability in the GTS NX MIDAS.

According to the calculation results, the stability of the slope is not ensured without reinforcement at the value of the actual coefficient of stability $\mathrm{K}_{\text {st fact. }}=1.15<\mathrm{K}_{\text {stn }}=1.2$ (Fig. 5).

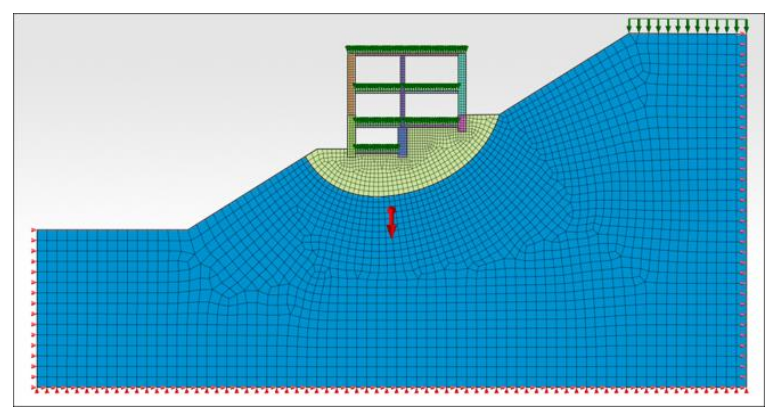

Fig. 5. The slope stability without reinforcement.

In the GTS NX MIDAS software package, the stability of the slope was calculated when it was strengthened in various ways [15]: with a wall from a series of bored piles of various lengths and diameters; thin-walled concrete retaining wall; reinforced geotextiles. The results of calculations in the GTS NX MIDAS showed the following:

- the slope stability is not ensured $\mathrm{K}_{\mathrm{st1}-3}=1.16<\mathrm{K}_{\mathrm{stn}}=1.2$ when reinforced with piles with a diameter of $\mathrm{d}=0.3 \ldots 0.5 \mathrm{~m}$ and a length $\mathrm{l}=2.6 \ldots 3.5 \mathrm{~m}$;

- the slope stability is minimally ensured at $\mathrm{K}_{\mathrm{st} 4}=1.21>\mathrm{K}_{\mathrm{stn}}=1.2$ at strengthening the slope base with a thin-walled concrete retaining wall of a height $\mathrm{h}=6 \mathrm{~m}$ with anchors;

- the best stability of the slope at $\mathrm{K}_{\mathrm{st} 6}=1.52>\mathrm{K}_{\mathrm{stn}}=1.2$ when reinforcing slopes with soil reinforced with geotextiles with a total layer thickness $h=0.5 \mathrm{~m}$ (Fig. 6). 


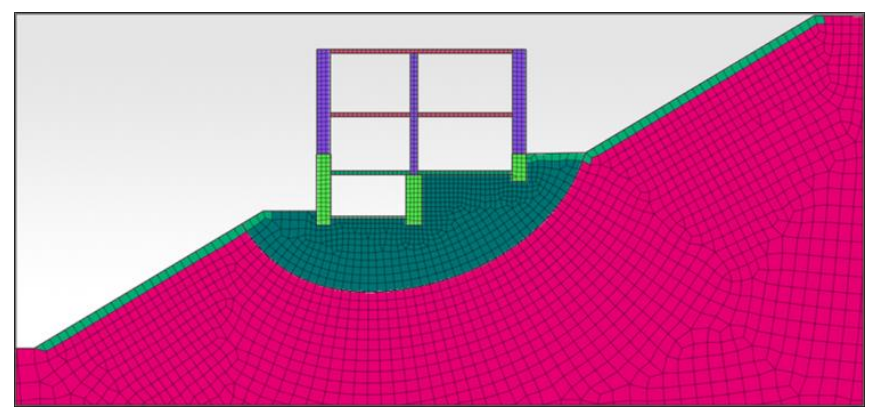

Fig. 6. - Strengthening the slope with the soil reinforced with geotextile.

\section{Discussion}

Adaptation of the building to modern needs is determined by the technogenic conditions of its exploitation. Research and monitoring of the base soils, as well as building wall structures for the period 2013...2018 show that their stable state is violated by prevailing modern technological conditions:

- the constant vibration loads from automobile traffic along the adjacent Aviatsionnaya and Bekhterev streets led to the accelerated development of cracks in the walls of the building;

- the additional load onto the edge of the slope from the constructed multi-story building violated the condition of the stability of the slope;

- continuous leakage of water from the sewage system led to an increase in the humidity of the sand - the base soil.

Calculations of the slope stability in the GTS NX MIDAS software package when strengthened with reinforced geotextiles showed the possibility of maintaining its stability.

The study of the soil conditions of the building base and the stability of the slope should be continued after all measures to adapt to modern needs are completed.

\section{Conclusions}

The analysis of the study of the soil foundation of the building - an object of cultural heritage - "Skuratova House" in Voronezh in order to adapt it to modern needs allows us to draw the following conclusions:

- the influence of modern technological conditions of historical urban areas on the soils of the foundation of the building was determined:

- violation of the conditions of the slope stability by additional load after the construction of new multi-storey buildings led to the development of slope processes;

- strengthening the slope allows one to maintain its stability in new technogenic conditions.

The results of the study can be used in the development of projects for monitoring the soil of the base and the development of engineering and geological processes in the historical city territory of Voronezh.

\section{References}

1. Federal law of 06.25.2002 N 73-Ф3, "On objects of cultural heritage (historical and cultural monuments) of the peoples of the Russian Federation", article 44 "Adaptation of the cultural heritage for modern use" (2019) 
2. SRP-2007, Set of Restoration Rules, 5th edition, Recommendations for research, survey, design and production work aimed at the preservation of cultural heritage objects (historical and cultural monuments) of the peoples of the Russian Federation. Moscow (2012)

3. GOST R 55528-2013. Composition and content of scientific and design documentation for the preservation of cultural heritage objects. Monuments of history and culture. General requirements. Moscow (2013)

4. GOST 31937-2011. Buildings and constructions. Rules for inspection and monitoring of the technical condition. Moscow (2012)

5. GOST R 55945-2014. General requirements for engineering and geological surveys and research for the preservation of cultural heritage sites. Moscow (2015)

6. SP 47.13330.2012. Updated edition of SNiP 11-02-96. Eng. Sur. for const. The main provisions, Moscow (2012)

7. SP 11-105-97. Eng. and geol. Surv. for const. Moscow (1998)

8. GOST 5180-84. Soils. Laboratory methods for determining physical characteristics. Moscow (1984)

9. GOST 12536-79. Soils. Laboratory methods for the determination of particle size (grain) composition. Moscow (1980)

10. GOST R56198-2014. Monitoring the technical condition of cultural heritage sites. Immovable monuments. General requirements. Moscow (2014)

11. GOST 25100-2011. Soils. Classification. Moscow (2012)

12. GOST 20522-96. Soils. Methods of statistical processing of test results. Moscow (1996)

13. A.V. Zhabko, The theory of calculating the stability of slopes and foundations. Analysis, characterization and classification of existing methods for calculating the stability of slopes, News of USMU, 4 (40) (2015).

14. V.K. Tsvetkov, E.G. Vlasova, N. Ya. Naumova, The dependence between the main parameters of homogeneous soil slopes and slopes in violation of their stability. Bulletin of VolgGASU, Constr. and arch., 11 (2008)

15. B.A. Khramtsov, A.A. Rostovtseva O.A. Lubenskaya, I.V. Simonov, Development of engineering measures to stabilize a landslide slope. Int. Res. J. 12-3 (19) (2013) 